\title{
Combination of tamoxifen and antisense human telomerase RNA inhibits glioma cell proliferation and anti-apoptosis via suppression of telomerase activity
}

\author{
YINGYI WANG ${ }^{1 *}$, ZHIMIN ZHOU $^{2 *}$, HUI LUO $^{1}$, ZHIFENG WU $^{2}$, JIONG GENG $^{2}$, WEIFENG MIU ${ }^{2}$, \\ YI PU ${ }^{2}$, NING LIU ${ }^{1}$, YONGPING YOU ${ }^{1}$ and ZHENGXIANG YANG ${ }^{2}$ \\ ${ }^{1}$ Department of Neurosurgery, The First Affiliated Hospital of Nanjing Medical University, Nanjing 210029; \\ ${ }^{2}$ Department of Neurosurgery, The Affiliated Wuxi People's Hospital of Nanjing Medical University, Wuxi 214023, P.R. China
}

Received May 31,2010; Accepted August 9, 2010

DOI: $10.3892 / \mathrm{mmr} .2010 .356$

\begin{abstract}
Accumulating evidence indicates that telomerase activity and human telomerase RNA (hTR) play a potentially crucial role in maintaining the malignant progression of human gliomas. Tamoxifen (TAM) induces cell growth inhibition by modulating several cellular activities, including signaling pathways and the cell cycle. In this study, we aimed to evaluate the effect of combination therapy with TAM and antisense hTR on malignant glioma growth in vitro. TAM treatment and the down-regulation of hTR expression by antisense hTR resulted in a significant suppression of cell growth and the induction of cell apoptosis through the inhibition of telomerase activity. The antitumor effect of treatment with TAM alone was found to be mediated in part by the down-regulation of telomerase activity and of PKC and IGF-1 expression. Our results indicate that TAM and antisense hTR may serve as a novel strategy for glioma therapy.
\end{abstract}

\section{Introduction}

Tamoxifen (TAM), a nonsteroidal triphenylethylene derivative, is a potent estrogen receptor (ER) antagonist commonly used in the treatment of breast cancer $(1,2)$. ER inhibition blocks the secretion of growth factors, including epidermal growth factor and transforming growth factor- $\alpha$, leading to the growth arrest

Correspondence to: Dr Zhengxiang Yang, Department of Neurosurgery, The Affiliated Wuxi People's Hospital of Nanjing Medical University, Wuxi 214023, P.R. China

E-mail: wuxiyangz@126.com

Dr Yongping You, Department of Neurosurgery, The First Affiliated Hospital of Nanjing Medical University, Nanjing 210029, P.R. China E-mail: yyp19@njmu.edu.cn

*Contributed equally

Key words: glioma, telomerase, telomerase RNA, tamoxifen, combination therapy of ER-positive cells. In addition to its cytostatic effects mediated through the ER, TAM is cytotoxic to ER-positive and ER-negative cells (3). Cell culture experiments on glioma cells (ER-negative) have shown that TAM at certain concentrations induces growth-inhibition and/or apoptotic cell death (4-6).

Telomeres are distinctive DNA-protein structures which cap the ends of linear chromosomes $(7,8)$. Three core components of the telomerase holoenzyme are human telomerase RNA (hTR), human telomerase reverse transcriptase (hTERT) and telomerase-associated protein (TP1) (9). hTR contains a template domain that serves as a reading frame for the extension of the G-rich 3' end of the telomeres by hTERT (10). Accumulating evidence indicates that its RNA component can be used as a template for synthesizing telomeric repeats to lengthen the telomere and cause cellular immortality, which is a critical event in tumor formation (11-13). Our previous and other studies have demonstrated that hTR and telomerase activity may play a key role in the development and progression of malignant gliomas, and that the inhibition or down-regulation of telomerase activity may potentially be used in the clinic as a novel target of gene therapy for malignant gliomas (14-17).

The purpose of this investigation was to down-regulate telomerase activity through the knockdown of hTR using a plasmid vector carrying antisense hTR cDNA in combination with TAM treatment in glioma cells, and to examine whether this combination inhibits tumor growth. Furthermore, we aimed to elucidate the molecular mechanisms of the inhibition of tumor growth after treatment with TAM and antisense hTR.

\section{Materials and methods}

Cell culture, transfection and tamoxifen treatment. The human glioblastoma cell line TJ905 was established in our laboratory (18). The rat glioma cell line C6 was obtained from the Institute of Biochemistry and Cell Biology of the Chinese Academy of Science (Shanghai, China). The cells were maintained in Dulbecco's modified Eagle's medium (DMEM; Gibco, USA) supplemented with $10 \%$ fetal bovine serum and incubated at $37^{\circ} \mathrm{C}$ with $5 \% \mathrm{CO}_{2}$. The plasmid pcDNA3.1-anti-hTR was kindly provided by Dr Xiuwen 
Liu (NIH, USA). pcDNA3.1-anti-hTR was transfected by lipofectamine (Invitrogen, Carlsbad, CA, USA) once the cells achieved 60-70\% confluence. After a 48-h transfection, the cells were harvested for further study. The cells were cultured in the presence or absence of increasing concentrations (5, $10,15,20$ or $30 \mu \mathrm{M}$ ) of TAM (Sigma, USA) for $24,48,72$, $96,120,144$ or $168 \mathrm{~h}$, and were divided into 4 groups: the control group, the TAM group, the antisense hTR group and the combined group.

MTT assay. Cells were plated at $10^{4}$ cells/well in 96-well plates with 6 replicate wells for each set of conditions. MTT $(20 \mu \mathrm{l})(5 \mathrm{~g} / \mathrm{l}$; Sigma) was added to each well each day for 6 consecutive days after the initial treatment, and the cells were incubated for an additional $4 \mathrm{~h}$. The supernatant was then discarded. DMSO $(200 \mu \mathrm{l})$ was added to each well to dissolve the precipitate. Optical density (OD) was measured at a wavelength of $550 \mathrm{~nm}$. The data points represent the mean of a minimum of 6 wells. The percentage of cell survival was calculated using background corrected absorbance as follows: percentage of cell viability $=100 \times$ (1-A of experimental well)/A of untreated control well.

Telomerase activity assay. Telomerase activity was measured by the polymerase chain reaction (PCR)-based telomeric repeats amplification protocol (TRAP) assay using the TRAPeze kit (Intergen Co., Oxford, UK). In brief, after extension of the substrate 5'-[32P]-end-labeled TS primer oligonucleotide (5'-AATCCGTCGAGCACAGAGTT-3') by telomerase, the enzyme activity products were amplified by PCR and resolved on $10 \%$ polyacrylamide gel. Each reaction product was amplified in the presence of a 36-bp internal TRAP assay standard. Protein extracts were also incubated at $85^{\circ} \mathrm{C}$ for $10 \mathrm{~min}$ to test their heat sensitivity. A TSR8 quantitation standard (which serves as a standard to estimate the amount of product extended by telomerase in a given extract) was included for each set of TRAP assays. The TRAP reaction was as follows: i) primer elongation: a $25-\mu 1$ reaction mixture was transferred into a tube suitable for PCR amplification, then $2 \mu \mathrm{l}$ of cell extract and sterile water were added for a final volume of $50 \mu \mathrm{l}$; the tubes were transferred to a thermal cycler and one cycle was performed at $37^{\circ} \mathrm{C}$ for $20 \mathrm{~min}$. ii) Telomerase inactivation: one cycle was performed at $85^{\circ} \mathrm{C}$ for $5 \mathrm{~min}$. iii) Amplification: the reaction mixture $(50 \mu \mathrm{l})$ contained $\mathrm{dNTP}$, Taq polymerase, [32P]-labeled-TS primer and RP primer (5'-GCGCGG CTTACCCTTACCCTTACCCTAACC-3'). Amplification was performed for 30 cycles, followed by denaturation at $94^{\circ} \mathrm{C}$ for $45 \mathrm{sec}$, annealing at $60^{\circ} \mathrm{C}$ for $45 \mathrm{sec}$, polymerization at $72^{\circ} \mathrm{C}$ for $45 \mathrm{sec}$, and a final step at $72^{\circ} \mathrm{C}$ for $5 \mathrm{~min}$.

Quantitative analysis was performed using Image-Quant software. Telomerase activity was quantified by measuring the telomerase ladder bands signal, and relative telomerase activity was calculated as the ratio to the internal standard using the following formula: $\left[\left(\mathrm{X}-\mathrm{X}_{0}\right) / \mathrm{C}\right] \mathrm{x}\left[\left(\mathrm{R}-\mathrm{R}_{0}\right) / \mathrm{Cr}\right]-1$ $\mathrm{x} 100=$ total product generated, where $\mathrm{X}$ is the heat-untreated sample, $\mathrm{X}_{0}$ is the heat-treated sample, $\mathrm{C}$ is the internal control of heat-untreated samples, $\mathrm{Cr}$ is the internal control of TSR8, $\mathrm{R}$ is the TSR8 quantitation control, and $\mathrm{R}_{0}$ is the negative control. The 293 cell line extract with telomerase activity was used as a positive control (provided with the kit).
Argyrophilic nucleolar organiser region (AgNOR) staining. AgNOR staining was performed according to the guidelines of the international committee on AgNOR quantitation (19). In brief, slides were moved from water to heat-resistant plastic Coplin jars, fully immersed in $10 \mathrm{mM}$ sodium citrate buffer (pH 6.0) and autoclaved at $120^{\circ} \mathrm{C}$ for $20 \mathrm{~min}$. After being cooled to room temperature in sodium citrate buffer, the slides were stained with silver for $13 \mathrm{~min}$ at $37^{\circ} \mathrm{C}$ in the dark using a solution of one volume of $2 \%$ gelatin in $1 \%$ aqueous formic acid and two volumes of $50 \%$ silver nitrate. As a final step, the sections were dehydrated and mounted in Canada balsam with no counterstaining. The AgNOR were counted in 100 randomly-selected neoplastic mast cells throughout the tumor at a magnification of x1,000. Individual AgNOR were resolved by focusing up and down while counting within individual nuclei. The average AgNOR counts/cell was determined by averaging these counts.

TUNEL assay. Apoptotic cell death was examined using the TUNEL method with an in situ cell death kit (Roche, USA) according to the manufacturer's instructions. Nuclei were counterstained with a DAPI karyotyping kit (Genmed, USA). Positive cells were visualized under a FluoView FV1000 confocal laser scanning microscope (Olympus, Japan) and analyzed by IPP5.1 (Olympus).

Immunohistochemical analysis. Briefly, the sections were incubated with primary antibody (1:100 dilution) overnight at $4^{\circ} \mathrm{C}$, then incubated with a biotinylated secondary antibody (1:200 dilution) at room temperature for $1 \mathrm{~h}$, followed by incubation with ABC-peroxidase reagent (1:200 dilution; Vector, USA) for an additional hour. After washing with Tris-buffer, the sections were stained with DAB (30 mg 3,3 diaminobenzidine dissolved in $100 \mathrm{ml}$ Tris-buffer containing $0.03 \% \mathrm{H}_{2} \mathrm{O}_{2}$ ) for $5 \mathrm{~min}$, rinsed in water and counterstained with hematoxylin. The antibodies used were antibodies to PKC and IGF-1 (Santa Cruz, USA). Negative controls were obtained by substituting primary antibodies with non-immune serum. The scores for the percentage of positive tumor cells were then calculated.

Statistical analysis. Statistical analysis was conducted by ANOVA or the t-test using SPSS 11.0 software. Significance was defined as $\mathrm{P}<0.05$.

\section{Results}

Combination of TAM and antisense hTR inhibits human glioma cell growth. To examine the cytotoxic effect of TAM, human glioma TJ905 cells were treated with various concentrations $(5,10,15,20$ and $30 \mu \mathrm{M})$ of TAM, and their response was examined at various time points $(24,48,72,96,120$, 144 and 168 h). Fig. 1A shows that the viability of the glioma cells remained almost unchanged in cells treated with TAM concentrations of $<10 \mu \mathrm{M}$ for the entire treatment duration. However, at a concentration of $15 \mu \mathrm{M}$ TAM, a cytotoxic effect was detected as of $72 \mathrm{~h}$ after treatment, and rapidly increased with an increase in the treatment time. At a concentration of $30 \mu \mathrm{M}$ TAM, $\sim 85 \%$ of the cells survived for $24 \mathrm{~h}$, only $40 \%$ of the cells survived for $96 \mathrm{~h}$, and viable cells reached their lowest point at $168 \mathrm{~h}$. This suggests that TAM plays a critical role in the induction of glioma cell death. 

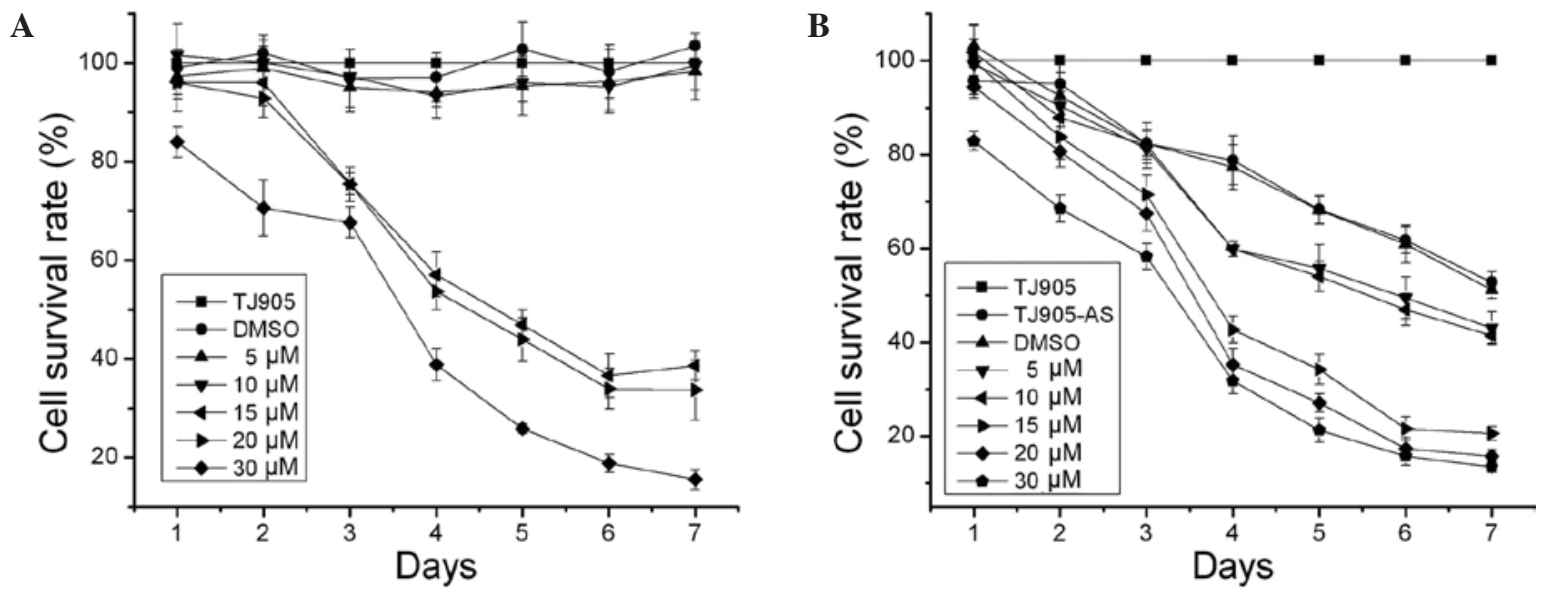

Figure 1. Cell viability of human glioma cells following treatment with TAM and antisense hTR. (A) TJ905 cells and (B) cells transfected with antisense hTR were cultured in the presence or absence of increasing concentrations $(5,10,15,20$ or $30 \mu \mathrm{M})$ of TAM for $24,48,72,96,120,144$ and $168 \mathrm{~h}$. The cell survival rate was measured by the MTT assay.

A

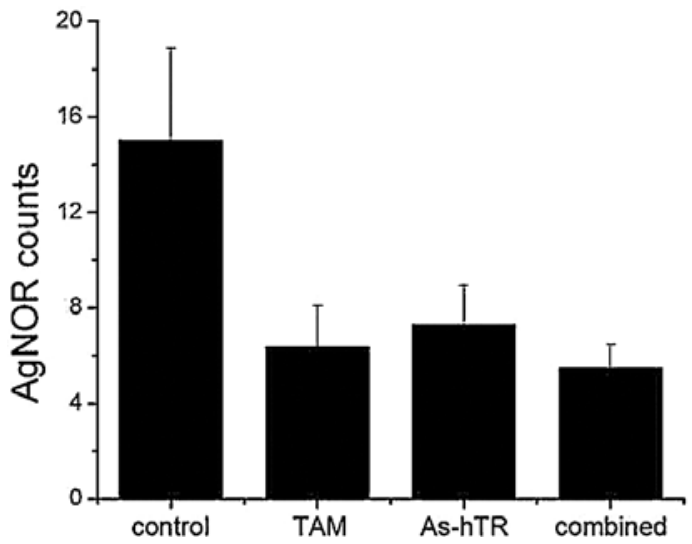

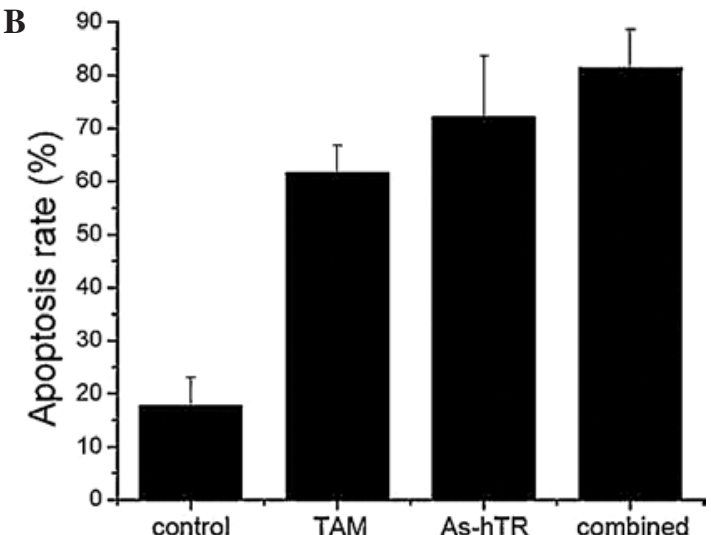

Figure 2. Effect of TAM and antisense hTR on cell proliferation and apoptosis in human glioma cells. TJ905 cells were treated with TAM (15 $\mu$ M) and/or antisense hTR. (A) Cell proliferation and (B) apoptosis were measured by the AgNOR and TUNEL assays. Data are presented as the mean \pm SD.

Our previous study showed that antisense hTR effectively inhibits the growth of TJ905 cells in vitro and in vivo (16). In order to evaluate the impact of TAM and antisense hTR combination treatment on glioma cell survival in vitro, an MTT assay was performed. TAM $(5 \mu \mathrm{M})$ and antisense hTR treatment resulted in marked cell growth inhibition compared to $5 \mu \mathrm{M}$ TAM or antisense hTR treatment alone. As shown in Fig. 1A and B, $15 \mu \mathrm{M}$ TAM combined with antisense hTR exerted a more significant effect on cell death than $15 \mu \mathrm{M}$ TAM or antisense hTR treatment alone, whereas $30 \mu \mathrm{M}$ TAM combined with antisense hTR induced slight cell growth inhibition. The data indicate that TAM and antisense hTR may have a cooperative role in glioma cell growth inhibition.

TAM and antisense hTR inhibit human glioma cell proliferation and induce cell apoptosis. To study the biological function of TAM and antisense hTR on glioma cell proliferation, the AgNOR assay was performed. Statistically significant AgNOR cell counts were found in the TAM, antisense hTR and combined groups compared to control group at $72 \mathrm{~h}$ after treatment. TAM and antisense hTR alone exerted less of an effect than the combined treatment (Fig. 2A). A TUNEL assay (Fig. 2B) revealed the cell apoptosis rate to be 17.78 \pm 5.27 , $61.64 \pm 5.12,72.28 \pm 11.32$ and $81.34 \pm 7.30 \%$ for the control, TAM, antisense hTR and combined groups, respectively $(\mathrm{P}<0.01)$. The results suggest that combination treatment with TAM and antisense hTR has the most robust effect on cell proliferation and apoptosis.

\section{TAM and antisense hTR repress telomerase activity in human} glioma cells. We hypothesized that the demonstrated ability of TAM and antisense hTR to inhibit human glioma cell proliferation and induce cell apoptosis in vitro may be attributable to their interference with telomerase activity; therefore, telomerase activity was assessed in glioma cells treated with TAM and antisense hTR using the TRAP method. The results revealed that telomerase activity in the TJ905 cells was markedly decreased by TAM and antisense hTR as compared to the activity in the control cells. As shown in Fig. 3, telomerase activity was $332.2 \pm 22.1,36.6 \pm 17.5,49.0 \pm 13.1$ and $15.8 \pm 4.1$ total product generated in the control, TAM, antisense hTR and combined groups, respectively $(\mathrm{P}<0.01)$. These data 
A

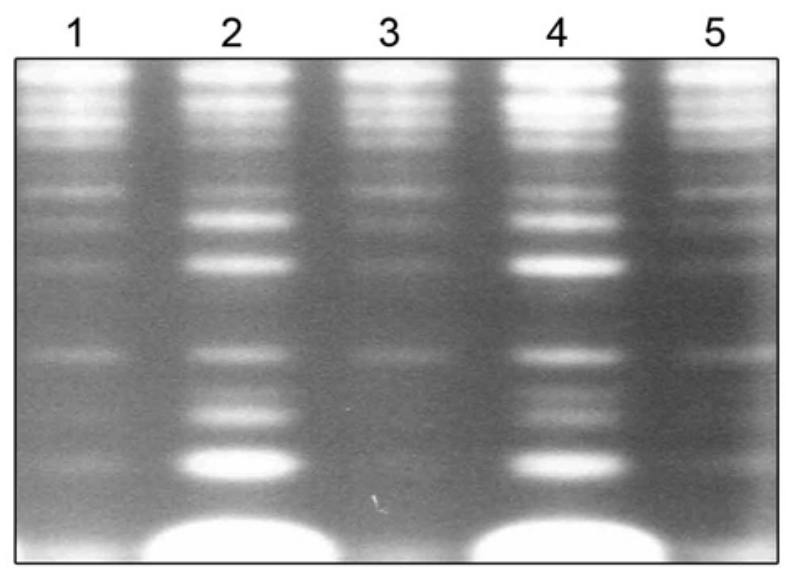

B

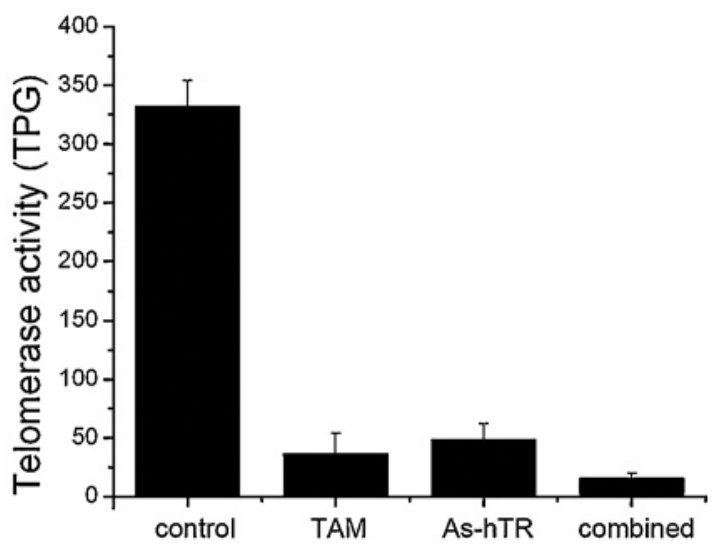

Figure 3. Effect of TAM and antisense hTR on telomerase activity in human glioma cells. (A) TJ905 cells were treated with TAM (15 $\mu \mathrm{M})$ and/or antisense hTR, and telomerase activity was measured by the TRAP assay. Lane 1, TAM; lanes 2 and 4, control; lane 3, combination treatment; lane 5, antisense hTR. (B) Numeric data. Representative telomerase activity data were obtained from three separate experiments.

A
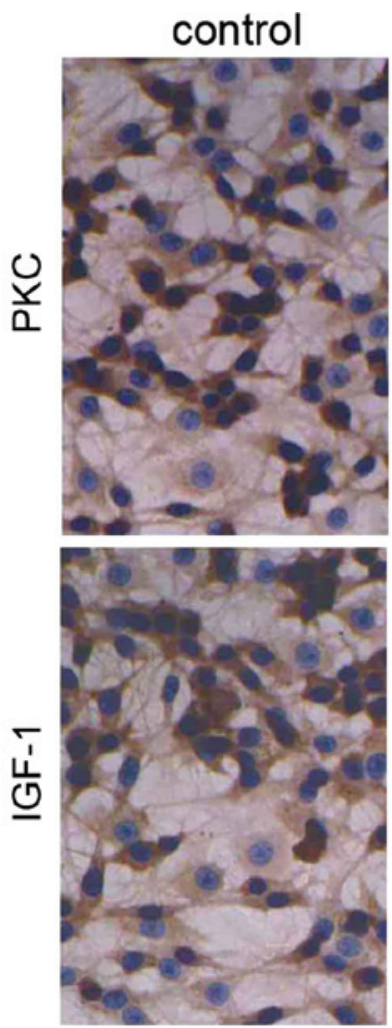

B

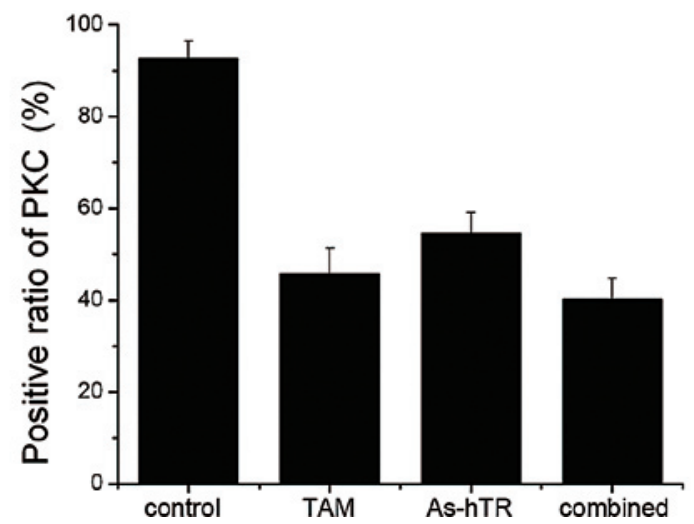

TAM
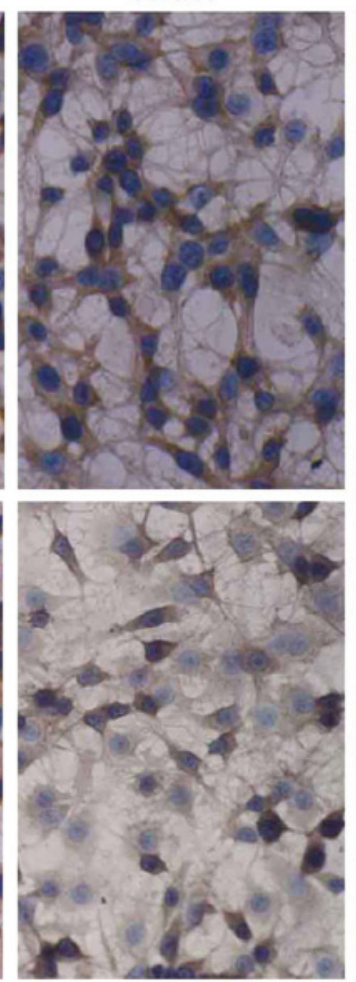

As-hTR combined
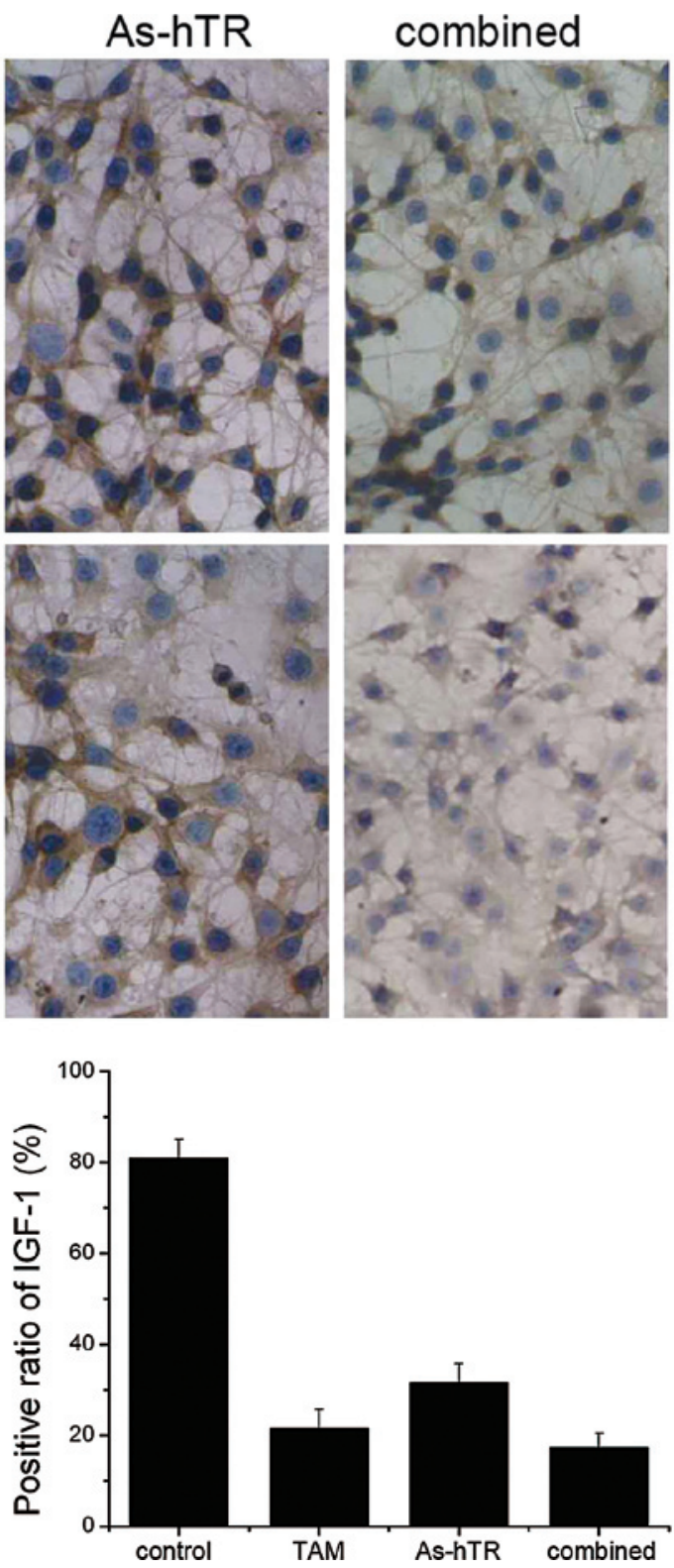

Figure 4. Effect of TAM and antisense hTR on PKC and IGF-1 expression in human glioma cells. TJ905 cells were treated with TAM (15 $\mu$ M) and/or antisense hTR, and PKC and IGF-1 expression was examined by immunohistochemistry. (A) Representative photomicrographs. (B) Numeric data. Data are presented as the mean $\pm \mathrm{SD}$. 
A

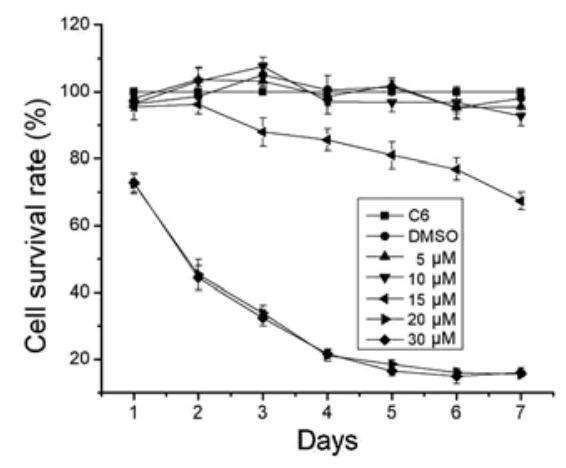

B

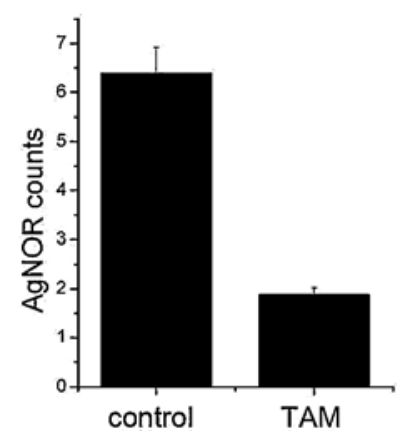

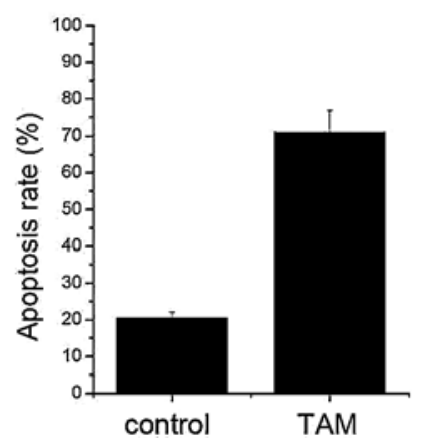

C
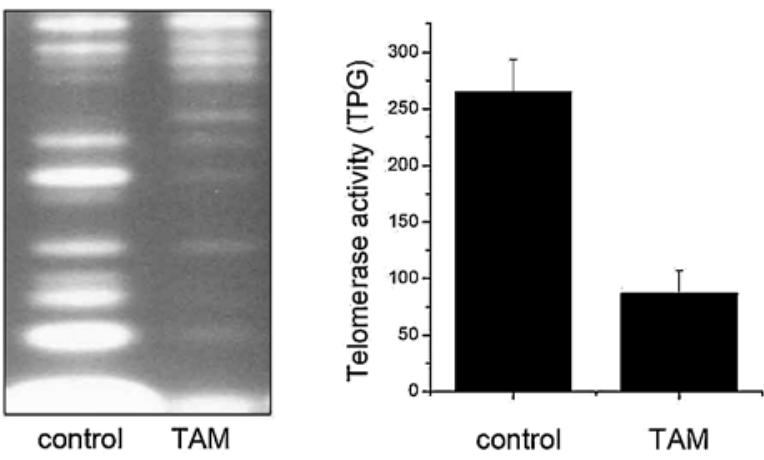

D

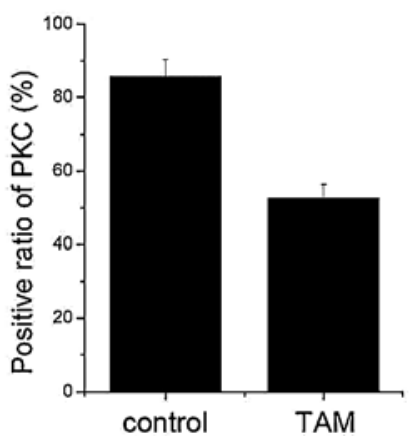

Figure 5. Effect of TAM on rat glioma cells. (A) C6 cells were cultured in the presence or absence of increasing concentrations (5, $10,15,20$ or $30 \mu \mathrm{M})$ of TAM for 24, 48, 72, 96, 120, 144 and $168 \mathrm{~h}$. The cell survival rate was measured by the MTT assay. (B) C6 cells were treated with TAM (15 $\mu \mathrm{M})$ and cell proliferation and apoptosis were measured by the AgNOR and TUNEL assays. (C) Telomerase activity was measured by the TRAP assay. (D) PKC and IGF-1 expression was examined by immunohistochemistry. Data are presented as the mean $\pm \mathrm{SD}$.

suggest that the effect of TAM and antisense hTR on the proliferation and apoptosis of human glioma cells occurs partly through the suppression of telomerase activity.

It has previously been reported that PKC and IGF-1 regulate telomerase activity, and that TAM inhibits the expression of PKC and IGF-1 (5,20-22). Thus, we explored changes in PKC and IGF-1 expression after TAM and antisense hTR treatment using immunohistochemistry. As shown in Fig. 4, a marked reduction in PKC was observed in TJ905 cells. Consistently, TAM and antisense hTR led to a marked suppression of IGF-1 protein expression.

TAM inhibits cell growth in rat C6 glioma cells. We demonstrated that TAM inhibits cell proliferation and induces cell apoptosis via the regulation of telomerase activity and PKC and IGF-1 expression in human glioma cells. However, the function and mechanism of TAM in other glioma cells, particularly rat glioma cells, have yet to be elucidated. Therefore, the antitumor effect of such approaches was further investigated using rat C6 glioma cells. The MTT assay revealed a similar trend of C6 cell response to TAM at various doses and treatment times, and a cytotoxic effect was detected after treatment with $15 \mu \mathrm{M}$ TAM for $72 \mathrm{~h}$ (Fig. 5A). Additionally, TAM decreased cell proliferation and increased cell apoptosis (Fig. 5B). Moreover, a significant reduction in telomerase activity was consistently detected by TRAP analysis. Similar effects on PKC and IGF-1 expression were achieved after treatment, in line with the experiments on human glioma cells.

\section{Discussion}

The present study revealed that treatment with a combination of TAM and antisense hTR inhibited cell proliferation and induced cell apoptosis in glioma cells due to the downregulation of telomerase activity and PKC and IGF-1 expression. Treatment with TAM alone to some extent suppressed the activity of telomerase and the expression of PKC and IGF-1, and affected glioma cell proliferation and apoptosis. The combined effects of TAM and antisense hTR most effectively modulated the molecules involved in these processes.

Telomerase acitivity is essential to maintaining the integrity of replicating tumor cells and to establishing immortality, and thus is required for the survival and proliferation of the majority of tumor cells. Telomerase expression has been detected in more than $90 \%$ of malignant tumors, including gliomas, but is absent in most normal somatic tissues $(23,24)$. hTR provides the template for the de novo synthesis of telomeric DNA and overcomes the 'end-replication problem'. In our previous study, treatment with antisense hTR resulted in the suppression of more than $75 \%$ of hTR mRNA, more than $55 \%$ of hTERT mRNA and more than $80 \%$ of telomerase acitivity in TJ905 glioma cells, and subsequently inhibited tumor growth in vitro and in vivo (16). Therefore, strategies targeting telomerase may be a novel approach for cancer gene therapy.

Treatment with TAM down-regulates hTERT expression and telomerase activity in various types of human cancer, including hepatoblastoma, breast and endometrial cancer $(25,26)$. Furthermore, PKC activity has been suggested to be 
crucial for the post-translational up-regulation of telomerase activity (20). In addition, IGF-I has been shown to stimulate telomerase activity in prostate cancer cells through a dual mode of action, including early rapid effects likely involving the phosphorylation of hTERT by Akt and the later up-regulation of hTERT expression (21). In this study, we confirmed a similar down-regulation of telomerase activity in human and rat glioma cells after TAM treatment. A marked reduction in PKC and IGF-1 expression was also observed. This indicates that TAM may down-regulate telomerase activity through the repression of PKC and IGF-1. These findings prompted us to examine the role of hTR knockdown and TAM treatment as a combination therapy for effectively controlling the malignant growth of gliomas. Our study showed that a combination of TAM with antisense hTR treatment resulted in a marked reduction in cell proliferation and the induction of cell apoptosis. However, further studies are necessary to delineate the molecular mechanisms behind the inhibition of gliomas following treatment with a combination of TAM and antisense hTR.

In conclusion, our study demonstrated that the knockdown of hTR and treatment with TAM effectively inhibited cell proliferation and induced the cell apoptosis of glioma cells through the down-regulation of telomerase activity. Therefore, the combination of TAM with antisense hTR may serve as a potential therapeutic regimen for effectively controlling the growth of glioma cells.

\section{References}

1. Gradishar WJ: Adjuvant endocrine therapy for early breast cancer: the story so far. Cancer Invest 28: 433-442, 2010.

2. Mustacchi G, Ceccherini R, Milani S, Pluchinotta A De Matteis A, Maiorino L, Farris A, Scanni A and Sasso F: Tamoxifen alone versus adjuvant tamoxifen for operable breast cancer of the elderly: long-term results of the phase III randomized controlled multicenter GRETA trial. Ann Oncol 14: 414-420, 2003

3. Mandlekar S, Yu R, Tan TH and Kong AN: Activation of caspase-3 and c-Jun NH2-terminal kinase-1 signaling pathways in tamoxifen-induced apoptosis of human breast cancer cells. Cancer Res 60: 5995-6000, 2000.

4. Kim YJ, Lee CJ, Lee U and Yoo YM: Tamoxifen-induced cell death and expression of neurotrophic factors in cultured C6 glioma cells. J Neurooncol 71: 121-125, 2005.

5. Tian F, Wu H, Li Z, Wang N, Huang J, Li C and Xie F: Activated $\mathrm{PKCalpha/ERK1/2}$ signaling inhibits tamoxifen-induced apoptosis in C6 cells. Cancer Invest 27: 802-808, 2009.

6. Zartman JK, Foreman NK, Donson AM and Fleitz JM: Measurement of tamoxifen-induced apoptosis in glioblastoma by cytometric bead analysis of active caspase-3. J Neurooncol 67: 3-7, 2004 .

7. Theimer CA and Feigon J: Structure and function of telomerase RNA. Curr Opin Struct Biol 16: 307-318, 2006.
8. Legassie JD and Jarstfer MB: The unmasking of telomerase. Structure 14: 1603-1609, 2006.

9. Weinrich SL, Pruzan R, Ma L, et al: Reconstitution of human telomerase with the template RNA component hTR and the catalytic protein subunit hTRT. Nat Genet 17: 498-502, 1997.

10. Lingner J, Hughes TR, Shevchenko A, Mann M, Lundblad V and Cech TR: Reverse transcriptase motifs in the catalytic subunit of telomerase. Science 276: 561-567, 1997.

11. Liu JP, Chen W, Schwarer AP and Li H: Telomerase in cancer immunotherapy. Biochim Biophys Acta 1805: 35-42, 2010.

12. Fletcher TM: Telomerase: a potential therapeutic target for cancer. Expert Opin Ther Targets 9: 457-469, 2005.

13. Mokbel K: The evolving role of telomerase inhibitors in the treatment of cancer. Curr Med Res Opin 19: 470-472, 2003.

14. George J, Banik NL and Ray SK: Combination of hTERT knockdown and IFN-gamma treatment inhibited angiogenesis and tumor progression in glioblastoma. Clin Cancer Res 15: 7186-7195, 2009

15. You Y, Geng X, Zhao P, Fu Z, Wang C, Chao S, Liu N, Lu A, Gardner K, Pu P, Kong C, Ge Y, Judge SI and Li QQ: Evaluation of combination gene therapy with PTEN and antisense hTERT for malignant glioma in vitro and xenografts. Cell Mol Life Sci 64: 621-631, 2007.

16. You Y, Pu P, Huang Q, Xia Z, Wang C, Wang G, Yu C, Yu JJ, Reed $\mathrm{E}$ and $\mathrm{Li} \mathrm{QQ}:$ Antisense telomerase RNA inhibits the growth of human glioma cells in vitro and in vivo. Int J Oncol 28: 1225-1232, 2006.

17. Zhao P, Wang C, Fu Z, You Y, Cheng Y, Lu X, Lu A, Liu N, Pu P, Kang C, Salford LG and Fan X: Lentiviral vector mediated siRNA knock-down of hTERT results in diminished capacity in invasiveness and in vivo growth of human glioma cells in a telomere length-independent manner. Int J Oncol 31: 361-368, 2007.

18. Wang SL, Li F, Pu PY and Wang GX: The establishment and characteristics of human glioblastoma cell lines TJ899 and TJ905. J Tianjin Med 24: 416-418, 1996.

19. Trere D: AgNOR staining and quantification. Micron 31: 127-131, 2000.

20. Liu JP: Studies of the molecular mechanisms in the regulation of telomerase activity. FASEB J 13: 2091-2104, 1999.

21 Wetterau LA, Francis MJ, Ma L and Cohen P: Insulin-like grow th factor I stimulates telomerase activity in prostate cancer cells. J Clin Endocrinol Metab 88: 3354-3359, 2003.

22. Kanter-Lewensohn L, Girnita L, Girnita A, Dricu A, Olsson G, Leech L, Nilsson G, Hilding A, Wejde J, Brismar K and Larsson O: Tamoxifen-induced cell death in malignant melanoma cells: possible involvement of the insulin-like growth factor-1 (IGF-1) pathway. Mol Cell Endocrinol 165: 131-137, 2000.

23. Shay JW and Bacchetti S: A survey of telomerase activity in human cancer. Eur J Cancer 33: 787-791, 1997.

24. You Y, Pu P, Peng Q, Xia Z, Huang Q, Wang C and Wang G: Telomerase activity and regulation in human neuroepithelial tumors. Zhonghua Wai Ke Za Zhi 40: 90-93, 2002.

25. Wang Z, Kyo S, Maida Y, Takakura M, Tanaka M, Yatabe N, Kanaya T, Nakamura M, Koike K, Hisamoto K, Ohmichi M and Inoue M: Tamoxifen regulates human telomerase reverse transcriptase (hTERT) gene expression differently in breast and endometrial cancer cells. Oncogene 21: 3517-3524, 2002.

26. Brandt S, Heller H, Schuster KD and Grote J: The tamoxifeninduced suppression of telomerase activity in the human hepatoblastoma cell line HepG2: a result of post-translational regulation. J Cancer Res Clin Oncol 131: 120-128, 2005. 